\title{
Effect of ambient conditions on n-heptane droplet evaporation
}

\author{
Jigang Wang, Xiaorong Wang, Guilong Ren, Kai Xiang \\ Institute of Mechanical Engineering, Jiangsu University of Science and Technology, Zhenjiang, \\ 212003, China.
}

Email:wjg_sun@126.com

\begin{abstract}
Based on the theory of heat and mass transfer, an evaporation model for single droplet in the convection heat air environment was established. By comparing the experimental data, the correctness of the model was verified. The effects of the initial droplet diameter, ambient temperature, ambient pressure and flow intensity on the n-heptane droplet evaporation characteristics was analyzed. The results showed that ambient temperature, ambient pressure and flow intensity has a great influence on the n-heptane droplet evaporation, and the ambient temperature is the main factor, when the ambient temperature increased from $400 \mathrm{~K}$ to $600 \mathrm{~K}$, the droplet lifetime decreased from $44 \mathrm{~ms}$ to $6.5 \mathrm{~ms}$, shortened by $85.23 \%$. Ambient temperature and flow intensity can accelerate n-heptane droplet evaporation, but the evaporation time was extended with the increase of the ambient pressure.
\end{abstract}

Keywords: Evaporation, Single Droplet, N-Heptane, Ambient Pressure, Flow Intensity.

\section{INTRODUCTION}

Droplet evaporation is very common in the power plants, such as gas turbine, steam turbine and internal combustion engine. The evaporation process of liquid droplets in an internal combustion engine cylinder can be studied by a single droplet evaporation. Study single droplet evaporation process plays an important role in the process of spray and combustion [1].

At present, there are two research methods to study single droplet evaporation, namely, experimental research and theoretical research. In the experimental study, the liquid droplet can be placed in a high temperature environment by means of the quartz wire suspension and acoustic levitation method, the droplet evaporation characteristics can use a high-speed camera take photos to study. However, the experimental methods are complicated and the current technical conditions are difficult to study the evaporation of liquid droplets under high pressure and high convective environment. By establish the theoretical model, theoretically study the evaporation characteristics of single droplet can make up for the deficiency of the experiment. HU Peng.et al researched the n-heptane single droplet evaporation characteristic in a $\mathrm{CO} 2$-water vapor environment. The results show that with the increase of ambient pressure, ambient temperature, the ignition delay and droplet lifetime were all shortened. The influence of ambient temperature on $n$ heptane droplet evaporation is greater [2]. DING Jixian.et al studied the effects of pressure convection environment on droplet evaporation characteristics by establish a n-heptane single droplet evaporation model in nitrogen atmosphere. The results show that in high temperature and strong convection environment, increasing the ambient pressure can promote the droplet evaporation, but in low temperature and weak convection environment, increasing the ambient pressure can delay droplet evaporation [3]. From the literature, n-heptane droplet evaporation characteristics under high temperature and high pressure atmosphere are different from the conditions above all, there are few studies on droplet evaporation at high pressure and high temperature conditions. Therefore, it is necessary to study the n-heptane droplet evaporation characteristics under high temperature and high pressure atmosphere.

In this paper, based on the theory of heat and mass transfer, an evaporation model for single $n$-heptane droplet under the convection heat air environment was established. The model can be used to calculate the droplet diameter variations during evaporation, then it can analyze evaporation characteristics. By comparing the experimental data, the correctness of the model is verified. The influence of the initial droplet diameter, ambient temperature, ambient pressure and flow intensity on n-heptane droplet evaporation characteristics were analyzed.

\section{CLACULATION METHOD}

\subsection{Evaporation model}

The droplet evaporation process is a very complex process, in order to facilitate calculation, the evaporation model is set up based on the following assumptions: (1) the droplet is 
spherically symmetric; (2) There is no temperature gradient inside the liquid droplet, and the temperature and composition in the space are evenly distributed; (3) The physical properties in space is uniform distribution, and $L e=1$.

Based on the above assumptions, establish energy conservation, mass conservation, and component conservation equations for a single droplet, the evaporation rate is calculated as follows [4]:

$m=\frac{\pi D k}{C_{p}} N u \ln \left(1+B_{M}\right)$

$B_{M}=\frac{Y_{s}-Y_{\infty}}{1-Y_{s}}$

$Y_{s}=\frac{x_{s} M}{x_{s} M+M_{\text {air }}\left(1-x_{s}\right)}$

$x_{s}=x \frac{P_{s a t}}{P}$

The flow velocity will lead to forced convection, the impact through the correction of $\mathrm{Nu}$ to consider.

$$
\begin{aligned}
& N u=2+\left(N u_{0}-2\right) / F\left(B_{M}\right) \\
& F\left(B_{M}\right)=\left(1+B_{M}\right)^{0.7} \frac{\ln \left(1+B_{M}\right)}{B_{M}} \\
& N u_{0}=2+0.552 \operatorname{Re}^{0.5} \operatorname{Pr}^{1 / 3} \\
& \operatorname{Re}=\frac{\rho_{\infty} D U}{\mu_{m}} \\
& \operatorname{Pr}=\frac{C_{p} \mu_{m}}{k}
\end{aligned}
$$

The droplet evaporation rate is the function of temperature, therefore droplet evaporation rate can be expressed by

$\dot{m}=4 \pi r^{2} \rho_{m} \frac{d r}{d t}$

The droplet mass flow is equal to the rate of droplet evaporation, combined with equation (1) and (10), Droplet diameter is expressed by

$$
\frac{d D}{d t}=-\frac{2 k}{C_{p} D \rho_{m}} N u \ln \left(1+B_{M}\right)
$$

$\mathrm{t}=0, D=D_{0}$, integrate formula (10), we obtained $D$ is
$D=\sqrt{D_{0}^{2}-\frac{4 k}{C_{p} \rho_{m}} N u \ln \left(1+B_{M}\right) \Delta t}$

\subsection{Thermal physical properties of liquid droplets and ambient gas mixtures}

The $n$-heptane droplet specific heat capacity is given by the formula (13) [5]:

$$
\begin{aligned}
& C_{p}=2.25 \times 10^{3}+1.11 \times 10^{3} \tilde{T}+1.87 \times 10^{3} \tilde{T}^{2} \\
& -4.89 \times 10^{3} \tilde{T}^{3}+5.16 \times 10^{3} \tilde{T}^{4}
\end{aligned}
$$

The saturated vapor pressure of $n$-heptane is given by the formula (14) [6]:

$$
\begin{aligned}
& P_{\text {sat }}=\left(0.082+1.078 \tilde{T}+8.707 \tilde{T}^{2}+11.03 \tilde{T}^{3}\right. \\
& \left.+64.967 \tilde{T}^{4}-40.802 \tilde{T}^{5}+7.74 \tilde{T}^{6}\right) \times 10^{5}
\end{aligned}
$$

Liquid density is given by the formula (15), (16) [5]:

$\tilde{T}<0.793$

$$
\begin{aligned}
& \rho_{m}=678.93-248.73 \tilde{T}-251.16 \tilde{T}^{2}+735.16 \tilde{T}^{3}- \\
& 882.37 \tilde{T}^{4}
\end{aligned}
$$

$\tilde{T}>0.793$

$\rho_{m}=-3.16 \times 10^{5}+8.04 \times 10^{5} \tilde{T}-5.10 \times 10^{5} \tilde{T}^{2}$

The viscosity of $n$-heptane is given by formula (17) [6]:

$\mu_{m}=\left(\frac{1}{1.53+\frac{T-20}{233}}\right)^{3.758}+273.15$

The thermal conductivity is caiculated by formula (18) :

$$
k=0.122-0.137 \tilde{T}
$$

where $\tilde{T}$ is normalized temperature, $\tilde{T}=\frac{T-T_{0}}{T_{0}}$

Binary diffusion coefficient is calculated by formula (19):

$D_{m}=\frac{0.00143 T^{1.75}}{p M_{A B}^{0.5}\left[\left(\Sigma_{v}\right)_{A}^{1 / 3}+\left(\Sigma_{v}\right)_{B}^{1 / 3}\right]^{2}}$

where $M_{A B}=2\left(\frac{1}{M_{A}}+\frac{1}{M_{B}}\right)^{2}, \Sigma_{v}$ is atomic diffusion volume. 


\subsection{Model validation}

In this section, the evaporation model is validated against the experimental data reported in Daif .et al [7]. In the experiment, the ambient temperature is $294 \mathrm{~K}$, the initial droplet diameter is $1.386 \mathrm{~mm}$, the initial droplet initial temperature is $290 \mathrm{~K}$, the ambient pressure is $0.1 \mathrm{MPa}$, the air flow intensity is $0 \mathrm{~m} / \mathrm{s}$.

Fig. 1 shows the experimental values and calculated values of n-heptane droplet evaporation. It is clearly to see, the calculated values is agree with experimental values very well. Therefore, the model can analyze the evaporation characteristics of n-heptane droplet evaporation.

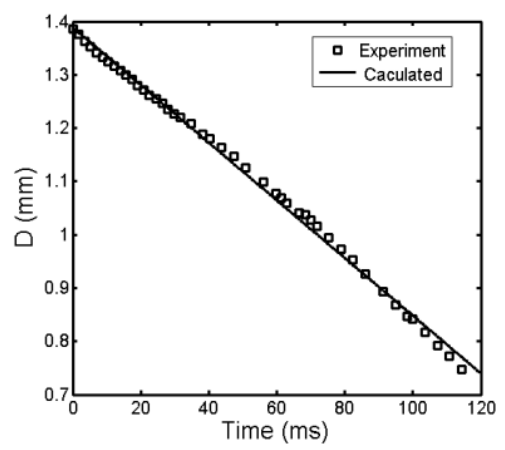

Figure 1. The experiment and calculated value of n-heptane droplet evaporation under normal temperature and pressure

\section{RESULTS AND DISCUSSION}

\subsection{The effect of initial droplet diameter}

Under ambient temperature $T=400 \mathrm{~K}$, ambient pressure $p=1 M P a$, flow intensity $U=1 \mathrm{~m} / \mathrm{s}$ and initial droplet temperature $300 \mathrm{~K}$, the evaporation characteristics of different initial diameter $(0.8 \mathrm{~mm}, 0.9 \mathrm{~mm}$ and $1.0 \mathrm{~mm})$ was calculated. And the effect of initial droplet diameter on n-heptane droplet evaporation was studied.

Fig. 2 given the variation of droplet diameter with different initial droplet diameter $(0.8 \mathrm{~mm}, 0.9 \mathrm{~mm}$ and $1.0 \mathrm{~mm})$.

Under the same ambient condition, the droplet lifetime increases with increasing the initial diameter. When the droplet diameter decrease from $1.0 \mathrm{~mm}$ to $0.9 \mathrm{~mm}, 0.8 \mathrm{~mm}$, the droplet lifetime decreasing from $61 \mathrm{~ms}$ to $52 \mathrm{~ms}, 44 \mathrm{~ms}$, shortened by $14.75 \%, 27.86 \%$, respectively. This is because droplet in a high ambient temperature environment, bigger droplet will need the longer response time rise to the ambient temperature under the same state.

\subsection{The effect of ambient temperature}

In this section, droplet diameter is $0.8 \mathrm{~mm}$, ambient pressure $p=1 M P a$, flow intensity $U=1 \mathrm{~m} / \mathrm{s}$ and initial droplet temperature $300 K$, the evaporation characteristics of different ambient temperature $(400 \mathrm{~K}, 500 \mathrm{~K}$ and $600 \mathrm{~K})$ was calculated. And the effect of ambient temperature on n-heptane droplet evaporation was studied.

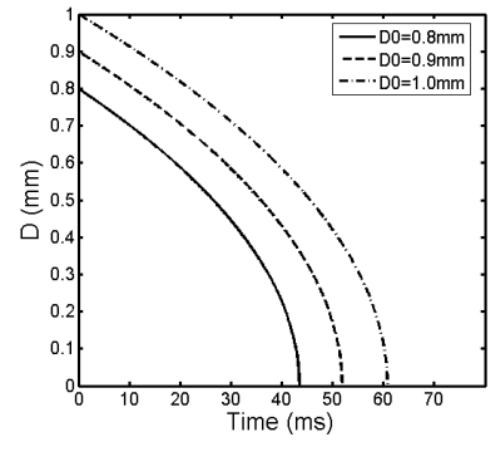

Figure 2. Time variations of droplet diameter with different initial droplet diameter

It can be seen from fig. 3 droplet lifetime decreases with increasing the ambient temperature. When the ambient temperature increase from $400 \mathrm{~K}$ to $500 \mathrm{~K}, 600 \mathrm{~K}$, the droplet lifetime decreasing from $44 \mathrm{~ms}$ to $33.5 \mathrm{~ms}, 6.5 \mathrm{~ms}$, shortened by $23.86 \%, 85.23 \%$, respectively. The temperature rises from $500 \mathrm{~K}$ to $600 \mathrm{~K}$, the droplet evaporation time decreases sharply, which is very different from the situation of ambient temperature increase from $400 \mathrm{~K}$ to $500 \mathrm{~K}$. This is because under high temperature, the physical properties of fuel changed dramatically, which led to the severely increase of evaporation rate. And this conclusion agrees with the conclusion in [2].

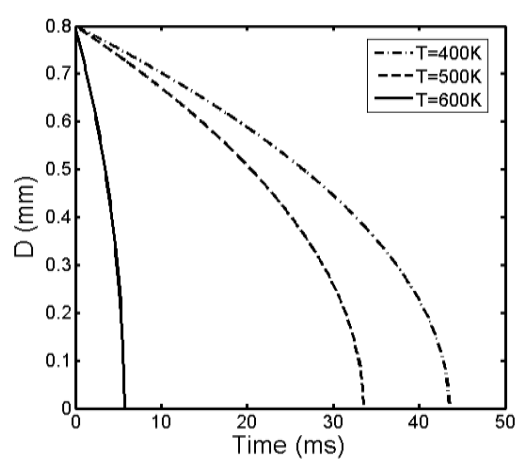

Figure 3. Time variations of droplet diameter with different ambient temperature

\subsection{The effect of ambient pressure}

In this section, droplet diameter is $0.8 \mathrm{~mm}$, ambient temperature $T=400 \mathrm{~K}$, flow intensity $U=1 \mathrm{~m} / \mathrm{s}$ and initial droplet temperature $300 K$, the evaporation characteristics of different ambient pressure $(1 M P a, 2 M P a$ and $3 M P a)$ was calculated. And the effect of ambient pressure on n-heptane droplet evaporation was studied.

In fig. 4. n-heptane droplet evaporation rate increases with the decreasing the ambient, this is consistent with the results of many experiments and conclusions [2-4]. When the ambient pressure increase from $1 M P a$ to $2 M P a, 3 M P a$, the droplet lifetime increased from $44 \mathrm{~ms}$ to $50 \mathrm{~ms}$, $55 \mathrm{~ms}$. It can be seen from fig. 5. diffusion coefficient is inversely proportional to ambient pressure, high ambient pressure will lead to small diffusion coefficient, and the low evaporation rate of droplets. 


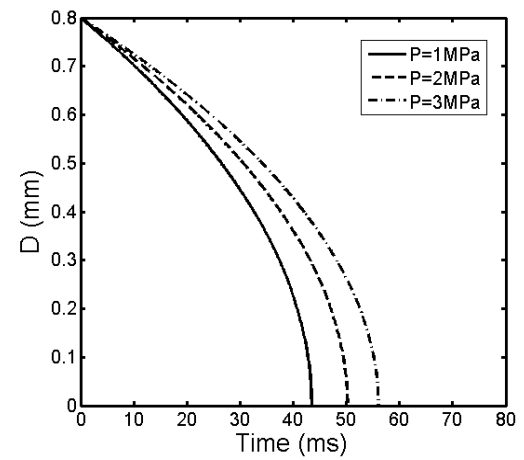

Figure 4. Time variations of droplet diameter with different ambient pressure

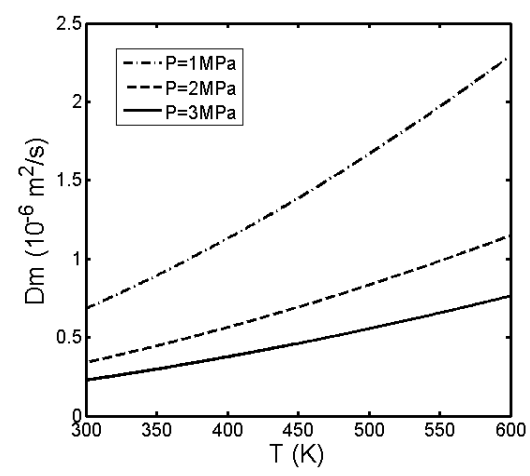

Figure 5. Temperature variations of diffusion coefficient with different ambient pressure

\subsection{The effect of flow intensity}

By changing the velocity of air movement, the influence of the flow intensity on the droplet evaporation characteristics can be simulated. In this section, droplet diameter is $0.8 \mathrm{~mm}$, ambient pressure $p=1 M P a$, ambient temperature $T=400 \mathrm{~K}$ and initial droplet temperature $300 K$, the evaporation characteristics of different flow intensity $(1 \mathrm{~m} / \mathrm{s}, 2 \mathrm{~m} / \mathrm{s}$ and $3 \mathrm{~m} / \mathrm{s}$ ) was calculated. And the effect of flow intensity on nheptane droplet evaporation was studied.

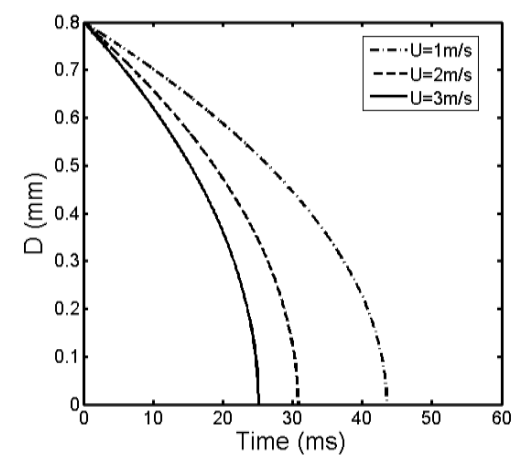

Figure 6. Time variations of droplet diameter with different flow intensity

Fig. 6 represent the time variations of droplet diameter with different flow intensity. It is clearly to see high flow intensity will accelerate droplet evaporation. When the flow intensity increase from $1 \mathrm{~m} / \mathrm{s}$ to $2 \mathrm{~m} / \mathrm{s}, 3 \mathrm{~m} / \mathrm{s}$, the droplet lifetime decreased from $44 \mathrm{~ms}$ to $30.5 \mathrm{~ms}$ and $25 \mathrm{~ms}$, shortened by $30.68 \%, 43.18 \%$, respectively. Therefore, air movement accelerated the evaporation process of the droplet.

\section{CONCLUSION}

1. Based on the theory of heat and mass transfer, an evaporation model for single droplet in the convection heat air environment was established. By comparing the experimental data, the correctness of the model is verified.

2. Ambient temperature, ambient pressure and flow intensity has a great influence on the n-heptane droplet evaporation, and the ambient temperature is the main factor. Ambient temperature and flow intensity can accelerate nheptane droplet evaporation, but with the increase of ambient pressure, the droplet evaporation time becomes longer.

3 . In droplet evaporation process, when the ambient temperature increased from $400 K$ to $600 K$, the droplet lifetime decreased from $44 \mathrm{~ms}$ to $6.5 \mathrm{~ms}$, shortened by $85.23 \%$. When the ambient pressure increase from $1 M P a$ to $3 M P a$, the droplet lifetime increased from $44 \mathrm{~ms}$ to $55 \mathrm{~ms}$. When the flow intensity increase from $1 \mathrm{~m} / \mathrm{s}$ to $3 \mathrm{~m} / \mathrm{s}$, the droplet lifetime decreased from $44 \mathrm{~ms}$ to $25 \mathrm{~ms}$, shortened by $43.18 \%$.

\section{ACKNOWLEDGMENTS}

This work was sponsored by National Natural Science Foundation of China (Grant No. 51306021). The authors would like to acknowledge the teachers and the students of Jiangsu University of Science and Technology for their helpful comments and advice during the preparation of this paper.

\section{REFERENCE}

[1] Kitano T., Nishio J., Kurose R., Komori S. (2013). Effects of ambient pressure, gas temperature and combustion reaction on droplet evaporation, Combust Flame, Vol. 161, No. 2, pp. 551-564. DOI: 10.1016/j.combustflame.2013.09.009

[2] Hu P., Song P., Xia S.W., Mei D.Q. (2013). Evaporation and combustion of a single n-heptane droplet in air with high concentration $\mathrm{CO}_{2}$ and stream, Transactions of CSICE, Vol. 31, No. 6, pp. 525-530. DOI: $10.16236 /$ j.cnki.nrjxb.2013.06.009

[3] Ding J.X., Sun F.X., Jiang R.Q. (2007). Effects of ambient pressure on fuel droplet evaporation in convective environments, Journal of Harbin Engineering University, Vol. 28, No. 10, pp. 11041108.

[4] Sun H.J., Zhang H.B., Bai B.F. (2008). Evaporation investigation of single droplet in high temperature fuel gas, Journal of Xi'an Jiao Tong University, Vol. 42, No. 7, pp. 833-837.

[5] Sazhin S.S., Kristyadi T., Abdelghaffar W.A., Heikal M.R. (2006). Models for fuel droplet heating and evaporation: comparative analysis, Fuel, Vol. 85, No. 12, pp. 1613-1630. DOI: 10.1016/j.fuel.2006.02.012

[6] Poling B.E., Prausnitz J.M., O’Connell J. (2000). The properties of gases and liquids, New York: McGrawHill.

[7] Daif A., Bouaziz M., Chesneau X., Ali C.A. (1998). Comparison of multicomponent fuel droplet 
vaporization experiments in forced convection with the Sirignano model, Experimental Thermal and Fluid Science, Vol. 18, No. 4, pp. 282-290. DOI: $\underline{10.1016 / \mathrm{S} 0894-1777(98) 10035-3}$

\section{NOMENCLATURE}

$\mathrm{BM}$

C

D

Dm

$\mathrm{k}$

$\mathrm{M}$

Le

$\mathrm{P}$
Spalding mass transfer number Specific heat capacity

Droplet diameter

Diffusion coefficient

Thermal conductivity

Molar mass

Lewis number

$\mathrm{Nu}$ Nusselt number

pressure
$\operatorname{Pr}$

$r$

U

$\mathrm{X}$

Y

\section{Greek symbols}

Viscosity

Density

\section{Subscripts}

$\begin{array}{ll}\text { s } & \text { Surface } \\ \infty & \text { Infinite } \\ \text { sat } & \text { Saturated } \\ 0 & \text { Initial value }\end{array}$

Prandtl number Droplet radius Velocity

Molar fraction

Mass fraction
Initial value 